This is an electronic reprint of the original article. This reprint may differ from the original in pagination and typographic detail.

Author(s): Saarinen, Jussi

Title: A critical examination of existential feeling

Year: $\quad 2018$

Version:

Please cite the original version:

Saarinen, J. (2018). A critical examination of existential feeling. Phenomenology and the Cognitive Sciences, 17(2), 363-374. https://doi.org/10.1007/s11097-017-9512-4

All material supplied via JYX is protected by copyright and other intellectual property rights, and duplication or sale of all or part of any of the repository collections is not permitted, except that material may be duplicated by you for your research use or educational purposes in electronic or print form. You must obtain permission for any other use. Electronic or print copies may not be offered, whether for sale or otherwise to anyone who is not an authorised user. 
This is the final "revise and resubmit" version of the article; please cite the published article. The final publication is available at:

http://link.springer.com/article/10.1007/s11097-017-9512-4/fulltext.html

DOI:10.1007/s11097-017-9512-4

\section{A critical examination of existential feeling}

\section{Introduction}

This article is a critical examination of Matthew Ratcliffe's theory of existential feelings. The notion of existential feelings has become increasingly salient in philosophical analyses of experience ranging from the psychopathological to the religio-mystical and moral (see e.g. Andrejč 2012; Benson, Gibson, \& Brand 2013; Bortolan 2016; Gerrans \& Scherer 2013; McLaughlin 2010; Saarinen 2014; Svenaeus 2013; Varga \& Krueger 2013; Wynn 2012). This bears witness to the appeal of Ratcliffe's long-standing efforts to conceptualize an area of affectivity that feels valid and important, but has nonetheless been insufficiently discussed in contemporary philosophy of emotion (see e.g. Ratcliffe 2005, 2008, 2015). The gain in visibility has also led to criticism and suggestions for improvement. While some discussants have voiced their concern over the ways in which Ratcliffe develops and applies classic phenomenological thinking (Fernandez 2014; Guignon 2009; Stolorow 2016; Warsop 2009), others have questioned the ontological commitments and ramifications of his theory (Manzotti 2012). Still others have attempted to refine and expand its basic conceptual scheme (Slaby \& Stephan 2008; Stephan 2012). In light of the above, Ratcliffe's theory continues to merit critical attention, especially as regards its more recent developments.

The critical focus and scope of this article will diverge from most foregoing discussion on the topic. As regards focus, I will not address how faithfully, cogently, or comprehensively Ratcliffe's theory utilizes ideas obtained from phenomenological thinkers such as Martin Heidegger, Edmund Husserl, and Maurice Merleau-Ponty. In other words, I will not provide a critical assessment of Ratcliffe's thinking in respect to its key philosophical sources. Instead, I will discuss his account on its own terms, i.e. as a self-standing system of argumentative premises, claims, and logical relations. As regards scope, prior criticism of Ratcliffe's theory has been relatively sparse and limited, presented mainly in short commentaries, book reviews, or in the service of some other overriding philosophical aims. In contrast, I will systematically analyze some of the core tenets of his account and explicate the ways in which these claims engender unaddressed concerns over the nature of existential feelings. ${ }^{1}$

\footnotetext{
${ }^{1}$ Riccardo Manzotti's (2012) externalist questioning of Ratcliffe's theory is perhaps the only critique that focuses on its core claims systematically and in relative depth.
} 
I will begin the article with an overview of Ratcliffe's characterization of existential feelings. This will pave the way for the subsequent discussion of three interrelated areas of concern for the theory. The first issue concerns their status as feelings, the second their mutual relations with intentional experience, and the third their presumed nonconceptuality. It is beyond the scope of this article to present an alternative or refined account of existential feelings. The aim is rather to draw attention to aspects of the theory that would benefit from further examination, and hence to advance ongoing discussion about existential feelings in particular and affective experience in general.

\section{Existential feelings}

In this section, I will summarize the main principles of Ratcliffe's account of existential feelings. This will provide a basic understanding of its key features and serve to set up the critical examination of Section 3.

Drawing mainly on the works of Heidegger, Husserl, and Merleau-Ponty, Ratcliffe maintains that feelings are classified as existential in virtue of two shared characteristics. Firstly, they are pre-intentional background feelings that structure experience as a whole (2015: 33-58). A key philosophical source for this notion is Heidegger's (1927/1996) discussion of Befindlichkeit and Stimmung. Befindlichkeit means that we always already find ourselves in a world that matters to us in some way. Finding oneself in the world is in turn affectively constituted by one or the other Stimmung, or 'mood'. Simply put, we are always attuned to the world through our moods. In this Heideggerian sense, we do not have moods in the same way that we have emotions, desires, or beliefs towards objects within the world. Instead we find ourselves in moods that disclose the world to us in a given, allencompassing manner. Ratcliffe accordingly highlights the fact that, viewed in a Heideggerian light, 'world' is not primarily an object of any intentional attitude. Rather, it is a backdrop against which we are able to adopt intentional attitudes of whatever kind towards objects or states of affairs within the world (Ratcliffe 2015: 19). Moreover, Ratcliffe maintains that experiencing things within the context of a pre-given world also implicates a sense of the possible. As he puts it, "to find oneself in a world is to have a sense of the various ways in which things might be encountered" (2015: 51). On this account, then, the pre-given world is fundamentally a space of possibilities in which moods constitute the kinds of possibility we are receptive to. For example, feeling fear towards any object in the world presupposes the sense that the world includes the possibility of threat or danger.

Despite drawing on the Heideggerian notion of Stimmung/mood, Ratcliffe opts to develop his theory in terms of 'existential feeling'. There are two main reasons for this (see Ratcliffe 2015: 58). First, Ratcliffe notes that the common English translation for Stimmung, 'mood', currently refers to a range of different phenomena, not all of which play the phenomenological role attributed to it by Heidegger. Thus, if Stimmung is translated as mood, there is a risk of conflating it with other relatively widespread meanings of mood that do not grasp its pre-intentional, world-disclosing nature. The second reason is exclusively 
theoretical. Ratcliffe maintains that Heidegger's notion of Stimmung is unnecessarily narrow in scope, especially in regards to its bodily nature. To make up for to this perceived shortcoming, Ratcliffe draws on Husserl and Merleau-Ponty to develop an account that emphasizes the bodily constitution of pre-intentional affectivity and of the horizon of possibility it discloses. Coining the term 'existential feeling' has thus allowed Ratcliffe to theoretically enrich the type of affectivity in question and to distinguish it from the prevalent understandings of mood.

The second key characteristic of existential feelings is that they are bodily feelings (2015: 59-64). On Ratcliffe's view, bodily experience and world-experience are inseparable. Applying this to existential feeling, Ratcliffe states that "a bodily feeling can at the same time be a sense of the salient possibilities offered by a situation" (2015: 59). To further specify the sense in which existential feelings are bodily, he distinguishes them conceptually from noematic and noetic bodily feelings (2015: 83-84). First, he designates as noematic those bodily feelings that are of the body or parts of the body. Simply put, these feelings have the body as their intentional object, e.g. feeling the pounding of one's heart. In noetic feelings, the body is in turn felt as that through which objects and states of affairs within the world are experienced. For example, while sitting in a delayed train trying to catch a flight on time, one's attention will likely be directed towards the world: to checking the time, listening to announcements, and so on (example from Colombetti \& Ratcliffe 2012: 147). In this case, the body provides a background sense of anxious urgency to the situation by feeling tight, tense, and confined. In short, noetic feelings are incorporated in intentionality directed beyond the body, yet through the body. In contrast, existential feelings constitute a distinct class of bodily feeling that is neither noematic nor noetic in character. Unlike the other two bodily feelings, existential feelings cannot be classified as intentional states directed towards anything. Rather, they provide the "overall context in which we have intentional states with noetic and noematic aspects" (Ratcliffe 2012: 39, 2015: 59, 83).

To elaborate, Ratcliffe identifies kinaesthesia, proprioceptive awareness, interoceptive awareness of visceral feelings, and tactile background feelings as the bodily "ingredients" of existential feelings (2008: 123; 2015: 59-64). These ingredients interact with each other in a variety of ways to produce a unitary "body sense" that has its own phenomenology (Ratcliffe 2008: 123-4; 2010a; 600). Existential feelings therefore "consist in a diffuse, background sense of bodily dispositions" rather than "non-phenomenological dispositions" to have certain kinds of experience (Ratcliffe 2015: 59, 51). For this reason existential feelings are not categorized as sub-personal or unconscious bodily states, processes, or dispositions. Ratcliffe thus provides a general framework for the bodily nature of existential feelings without committing to any account of their specific bodily correlates. Existential feelings are not usually felt as bodily nor are they commonly objects of conscious awareness. Instead, an existential feeling simply "is the way in which one finds oneself in the world" (Ratcliffe 2008: 129), while a shift in the feeling is felt accordingly as "a changed relationship to the world as a whole" (2008: 124).

As regards the role of existential feelings in structuring experience, not only do they disclose a world of possibilities, but also constrain that which is felt to be possible. More 
light may be shed on the restrictive aspect of existential feelings by comparing them to the familiar phenomena of moods and emotions. It is uncontroversial that being in a given mood affects the types of episodic emotions one is likely to feel. For example, a general mood of being persecuted tends to induce feelings of suspicion rather than compassion (although this is not necessarily so). Likewise, experiencing a certain emotional episode is likely to involve certain kinds of thoughts. For instance, feeling afraid of someone will most probably incorporate the distinctive judgment that that person is threatening, which will in turn engender associated thoughts about escaping or defusing the situation. In short, moods and emotions commonly frame what we feel and think in any given situation. In this relatively loose sense they also shape our intentional experience.

Compared to moods and emotions, Ratcliffe suggests that existential feelings influence feeling and thinking in a more determinative and profound manner. Existential feelings do not merely color experience or tend to make some intentional attitudes more prevalent or appropriate than others. Instead, they constrain the kinds of intentional experiences we are capable of having at all. For example, Ratcliffe states that the "range of emotions - and intentional states more generally - that we are able to adopt is thus dependent on the kinds of significant possibility that we are open to" (2010a: 604, my italics; see also 2013b: 159-160; 2015: 130). This stronger claim hinges on a distinction between instances of possibility and kinds of possibility (Ratcliffe, 2015: 51). For example, 'I fear that $q$ ' or 'I am afraid of $p$ ' are instances of a presupposed possibility of 'being threatened'. If one were incapable of experiencing things as threatening, one would not be able to experience this particular $q$ or that given $p$ as frightening. Importantly, Ratcliffe claims that this sense of possibilities is a felt aspect of our experience. To emphasize this point, he asserts that our "access to kinds of possibility is itself integral to experience (rather than being a nonphenomenological disposition to have certain kinds of experience)" (2015: 51). Ratcliffe suggests that the inseparable link between existential feelings and felt possibilities becomes especially salient when existential feelings undergo notable changes, e.g. in severe depression or psychosis. Such psychopathological states demonstrate that "changes in the overall style of experience, in existential feeling, are shifts in the kinds of possibilities one is receptive to" (Ratcliffe 2015: 51). For example, a profound loss of existential hope does not cancel out however many particular intentional hopes, it cancels out the possibility for a kind of intentional state altogether, namely the attitude of hope itself (Ratcliffe 2015: 130). On the whole, then, existential feelings are presumed to set the parameters for intentional experience, and are thus characterized as operating at a deeper level than moods and emotions.

Besides affect, Ratcliffe argues that existential feelings have a determinative effect on cognition. Broadly put, he suggests that one's overall cognitive style has an existential affective basis (2015: 70-74). More specifically, he claims that existential feelings restrict our options for belief and bias us toward the adoption of certain kinds of belief. Viewed in this light, at least some beliefs can be interpreted as expressions of existential feeling, e.g. the fundamental belief that life is meaningless. Hence, "what look like attitudes towards specific propositions are often expressions of how a person finds herself in the world" (Ratcliffe 2015: 146). To be sure, beliefs in the given sense do not consist in "mere 
intellectual play" or of "putting ticks next to propositions"; rather, they are fundamental, cogent beliefs that demand a feeling of certainty, "convictions that matter to us most" (2015: 274-5). In conjunction with belief formation, Ratcliffe suggests that existential feelings also influence the form and content of the autobiographical narratives we articulate about ourselves (2015: 151). On this account, in various instances of belief formation and selfnarration "the route is from the [existential] feeling to its conceptualization and articulation" (2015: 148).

To summarize, Ratcliffe defines existential feelings as pre-intentional bodily feelings that constitute a changeable background sense of possibility and reality. Crucially, intentional experience always presupposes existential feeling, and this applies to both affective and cognitive aspects of experience. Without the existence of a certain kind of existential feeling, then, associated kinds of emotions and propositional attitudes would not be possible or intelligible. This does not entail that existential feelings causally determine the form and content of occurrent intentional states, or even which states actually occur. They do, however, determine whether or not those kinds of intentional states are possible or intelligible to begin with.

\section{Three problematic areas in the theory of existential feelings}

In this section, I will identify and discuss three interrelated problems arising from Ratcliffe's characterization of existential feelings. The first problem concerns their status as feelings, the second their mutual relations with intentional experience, and the third their presumed nonconceptuality.

\subsection{Feeling existential feelings}

How, exactly, are existential feelings felt? There are two interrelated senses in which their felt nature is ambiguous. Both of these uncertainties stem from what I will refer to as Ratcliffe's basic dependency claim. To reiterate, Ratcliffe maintains that to be able to feel fear, hope, etc. towards anything within the world, one must find oneself in a pre-given world that incorporates the possibility of threat, some future good, and so on. Crucially, he argues that these possibilities are felt aspects of experience rather than "nonphenomenological dispositions" (Ratcliffe 2015: 51). In effect, the possibility and intelligibility of intentional states depends on existential feeling - not causally, but precisely in regard to their making sense. (See Ratcliffe 2010a: 604, 621; 2012: 39; 2013a: 600; 2013b: 159-160; 2015: 51, 59, 83, 130.)

This basic dependency claim has two important theoretical consequences that have not been analyzed in sufficient detail. First, the claim entails that occurrent intentional emotions require a concurrent existential feeling that simultaneously enables their possibility and intelligibility. That is, if a certain existential feeling is presumed to provide the experiential backdrop within which a particular emotion makes sense, it must necessarily co- 
exist with that emotion. If the existential feeling were to dissipate or did not exist, the grounds for the possibility and intelligibility of the intentional emotion would be accordingly lost or absent. Second, the dependency claim entails that most existential feelings must be sufficiently constant for them to be capable of systematically and reliably enabling the associated kinds of intentional states. Case in point, Ratcliffe argues that existential hope, for instance, is "not something people occasionally have"; instead, it is "something most of us have most of the time, a context in which our various hopes are formed, nurtured, and lost" (2013a: 604, my italics). This means that the overall space of possibilities that incorporates existential hope must perpetually involve the felt possibility of some future good. To be logically consistent, this constant sense of possibility must apply to all other emotional states we are regularly capable of as well, including fear, anger, sadness, joy, and so on.

The joint issues of concurrence and constancy complicate the feeling-aspect of existential feelings in two respects. The first problem pertains to the distinct sense in which they are felt as background bodily feelings. If, as Ratcliffe maintains, existential feelings are pre-intentional bodily feelings (2015: 59-64, 83-84), and intentional emotions commonly incorporate noetic bodily feelings (Ratcliffe 2008: 35-36), both types of background feeling must somehow be felt together, simultaneously. To elucidate why this poses a problem, let us examine anger. Ratcliffe's discussion of emotions (2008: 17-35) suggests that, in the main, episodes of anger are noetically structured: bodily feelings of palpitation, muscle tension, perspiration, flushing, etc. are incorporated into the experiential coloration of the intentional object of anger. In short, the noetic feeling is a diffuse, background bodily sense that contributes to the experiencing of the object as provocative and offensive. To this noetic background Ratcliffe adds another, more fundamental backdrop: an existential bodily feeling that makes the emotional episode possible and intelligible to begin with (2008: 37-38; 2015: 83-85). In the case of anger, the existential feeling can be characterized as the felt possibility that objects in general can be disclosed as provocative and offensive. ${ }^{2}$ On this account, the feeling body bifurcates so that one type of feeling constitutes the intentional aspects of the anger while another type of feeling simultaneously constitutes its possibility and intelligibility. Yet the feeling body is also felt as a diffuse background to the overall, unitary experience of anger. How, then, are the two diffuse background bodily feelings associated with each other and the unitary feeling of anger? How does the co-existence of the two background feelings play out on the bodily and phenomenal levels? Moreover, is it parsimonious to suggest that two concurrent feelings are needed for affectively experiencing an object as provocative and offensive?

The second issue concerns the sense in which existential feelings are felt as spaces of possibility. To repeat, Ratcliffe's dependency claim entails that most existential feelings must be sufficiently constant for them to be capable of systematically and reliably enabling the standard range of emotions. This in turn entails that at any given moment we must feel or sense the world as simultaneously disclosing the possibility of threat, some

\footnotetext{
${ }^{2}$ It is worth noting that in both existential and noetic feelings the body is felt as that through which the world is disclosed: in the former pre-intentionally as a possibility space and in the latter as specific kinds of intentional objects.
} 
future good, provocation/offense, and so forth ad absurdum. This seems to be a rather demanding and counterintuitive view of everyday experience. Consider fear. Presumably the sense of possible threat is elevated in strange and uncertain situations. But is this openness toward the possibility of being threatened a constantly felt bodily sense? Simply put, it is challenging to grasp the sense in which one would feel that the world is possibly threatening in situations where there is nothing potentially threatening in one's mind or environment and this alongside all other felt possibilities. Indeed, it appears that in everyday experience some existential feelings are pushed so far into the background that they in effect cease to be felt altogether. If this is the case, would it not be experientially more accurate to maintain that, in the changing circumstances of day-to-day life, some emotional possibilities become phenomenally more salient while others remain entirely inconspicuous?

In response to these concerns, one might point out that Ratcliffe's theory permits that "the space of significant possibilities in which we find ourselves need not itself be phenomenologically conspicuous (although it can be)" (Ratcliffe 2010a: 605, my italics). Indeed, according to Ratcliffe we "seldom notice" existential feelings; "they become salient only when they shift or take on a form that involves strangeness, novelty, unpleasantness, and/or lack" (2015: 39). Hence, if existential feelings are inconspicuous most of the time, they generally need not be felt constantly and/or concurrently with other feelings. But this response only serves to highlight the problem in question. Even if existential feelings are ordinarily inconspicuous, on Ratcliffe's account they can never be completely inconspicuous. In other words, they must be felt minimally and in some sense to qualify as something more than sub-personal or unconscious bodily states, processes, or dispositions. That being so, the sense in which one could feel two concurrent background bodily feelings during a unitary emotional episode is reinstated as an issue that calls for further phenomenological clarification. The same experiential uncertainty applies equally to the sense in which one could constantly feel innumerable kinds of emotional possibilities. All in all, then, we may question whether it is tenable to delineate existential feeling as a phenomenologically distinct type of feeling in the proposed concurrent and constant (yet inconspicuous) bodily sense. On the same note, we may ask whether it is plausible to designate as 'feelings' aspects of the experiential background that rarely, if ever, shift into the field of reflective consciousness.

\subsection{The bi-directional relationship between existential feelings and intentional experience}

The relationship between existential feelings and intentional states can be understood as bi-directional in the following sense. On the one hand, the intentional states that one is capable of depend on and are constrained by one's pre-given existential feelings. On the other, these intentional states are taken to influence the very existential feelings that constitute them (Ratcliffe 2008: 40; 2010b: 367; 2015: 146-150). Ratcliffe discusses various states, experiences, and processes that can modify existential feelings (e.g. self-narratives, beliefs, and interpersonal interactions) (2015: 146-150, 213-218). However, if the constraints placed by existential feelings are considered primary, by which mechanisms and to what extent can intentional states affect existential feelings? Ratcliffe touches on this issue by 
acknowledging his uncertainty over how our understandings of events actually shape our existential feelings. He asks, "But how could an intentional state somehow 'act upon' its own conditions of intelligibility?", and by way of answer, concedes: "It is not clear to me that much more can be said from a phenomenological perspective - it simply happens, just as existential changes can happen when one is sick, tired or intoxicated (2015: 151fn.). As it stands, it is not sufficiently clear how existential feelings are, and can be, affected by intentional states.

There are at least two factors that contribute to this uncertainty. First, although Ratcliffe maintains that existential feelings determine and constrain intentional experience, he does not take a definitive position on the strength of this dependence relation. In general, he affirms that "it is plausible to maintain that anyone incapable of experiencing things as significant in some way will also be incapable of the associated emotion type(s)" (Ratcliffe 2015: 130; see also 2013a: 600). This evinces a strong dependence relation, from which it would follow that the intentional states capable of affecting existential feeling must be states of the kind that the current existential feeling allows for. Loss of existential hope, for example, would entail that intentional hope states are categorically ruled out and therefore unavailable for modifying the underlying, hopeless existential feeling. However, such strong determinism would seem rather extreme. A more moderate view of the dependence relation would allow for intentional states that are not entirely consonant with the space of possibilities that the current existential feeling discloses. Either way, it would be important to clarify the extent to which intentional states are presumed to depend on existential feelings.

The second problematic factor is that, in the course of Ratcliffe's theorization, 'existential feeling' seems to refer to a variety of phenomena, making its conceptual boundaries somewhat indefinite. It is not always sufficiently clear whether existential feeling should be taken to designate an entire background space of felt possibilities (an overall affective 'style'; Ratcliffe 2015: 51, 85), a specific aspect of this space (e.g. stable and inconspicuous 'existential hope'; Ratcliffe 2013a), a felt change in this space (e.g. a conspicuous feeling of the world as 'overbearing' or 'suffocating'; Ratcliffe 2005: 48), or all of these interchangeably. Each option leads to different ways of conceptualizing the influence intentional states may have on existential feelings. Broadly put, much hinges on whether existential feelings are identified as background affective styles or consciously occurring episodes. Ratcliffe holds that, for the most part, existential feelings just are, perpetually operating in the backdrop of consciousness to tacitly constitute a space of possibilities. Taken as diffuse, background bodily senses or combinations thereof, existential feelings are difficult to single out and access as objects of direct conscious manipulation. If, on the other hand, we regard them as phenomenally salient episodes, they would seem to be more accessible to conscious regulation. Consider, for example, Ratcliffe's depiction of the feeling of strangeness that may arise as one explores a place while sick, tired, or jetlagged (2015: 63). This feeling may "culminate in an all-enveloping sense of one's relationship with the world being somehow 'not quite right', 'out of kilter'” (Ratcliffe 2015: 63). As a relatively salient episodic feeling, such strangeness seems easier to identify and, in all likelihood, more 
amenable to (cognitive) regulation than a diffuse and inconspicuous bodily sense (see Stephan 2012, for strategies of existential feeling regulation).

In sum, the nature of the bi-directional relationship between existential feelings and intentional experience calls for further clarification. To begin with, it would be important to elaborate on the strength of the dependence relation between existential feelings and intentional states, and to elucidate the nature of existential feelings as diffuse background senses or consciously salient episodes (or as both).

\subsection{The non-conceptual nature of existential feelings}

Ratcliffe maintains that existential feelings are categorically non-conceptual (or preconceptual) (2008: 39; 2010b: 368). As such, "they do not incorporate judgments or appraisals of any kind", and by implication, "do not incorporate any conceptual content" (Ratcliffe 2010b: 368). This may signify one of two things: 1) that existential feelings do not incorporate conceptual content but do incorporate non-conceptual content, or 2) that existential feelings are devoid of content altogether. Ratcliffe implies the latter in stating that an "existential feeling is a space of possibilities within which we experience, think, and act, as opposed to being an experience or thought content" (2010b: 368, my italics). This echoes the Heideggerian notion that moods are not internal psychological states with conceptual or non-conceptual contents, but rather pre-given ways of finding ourselves in the world. On this view, existential feelings function as the background context in which conceptual and nonconceptual mental states are necessarily embedded. In any case, it is clear that Ratcliffe considers existential feelings to at least be devoid of conceptual content. ${ }^{3}$

Let us examine Ratcliffe's account of existential guilt in light of this claim (see 2010a; 2015: 132-145). To refine our phenomenological grasp of guilt feelings, he identifies the following types of guilt: a) Feeling guilty about something specific, b) feeling guilty about something but not knowing what, c) feeling that one really is guilty of something specific, d) feeling guilty, and finally, e) feeling irrevocably guilty (Ratcliffe 2015: 133). Whereas the first three are intentional states, the latter two are designated as pre-intentional existential forms of guilt. That is the case because feeling (irrevocably) guilty is a profound alteration in one's sense of possibilities, i.e. it renders certain kinds of intentional state unintelligible. Instead of being directed at specific actions or deeds, existential guilt feels integral to one's whole being. The deepest type of existential guilt is "exclusively self-

\footnotetext{
${ }^{3}$ Riccardo Manzotti (2012) has questioned whether existential feelings can be object-less feelings (and hence, free of representational content). He argues that existential feelings should not be designated as object-less feelings, but rather as feelings with a special kind of existential object, namely, the "subject as a whole" (2012: 95, see also Slaby and Stephan 2008: 511-513). The existence of content-less/object-less feelings is an overarching issue that bears on possible conceptualizations of existential feeling. However, addressing this broad topic in any further detail falls beyond the scope of this article. My more limited focus is on whether Ratcliffe's own characterization of existential feelings entails, at least in some cases, the need for conceptual content.
} 
directed", yet "does not rest on any kind of judgment (moral or otherwise) regarding one's deeds" (Ratcliffe 2015: 143, 145).

Ratcliffe designates existential guilt as 'guilt' due to its structural similarity with intentional guilt. In his view, intentional guilt involves not feeling pleased about a past deed $p$, not being able to do $q$ rather than $p$, and not feeling connected to others in virtue of $p$ (Ratcliffe 2015: 139). Ratcliffe suggests that these are precisely the kinds of intentional states that are lost in existential guilt: "one cannot 'feel pleased about something', 'feel able to do something meaningful', or 'feel connected to somebody" (2015: 139). However, these features seem too general to distinguish guilt from other affective states. It is widely held that guilt also incorporates a negative evaluative judgment concerning a personal deed or oneself. To be fair, Ratcliffe also acknowledges that a common theme in guilt is the "sense of having done wrong or of being intrinsically flawed" (2015: 134), and involves "estrangement from others, in whose eyes one has done wrong" (2015: 138). But if that is indeed the case, it is unclear how these more specific evaluative features fit in with the scheme of structural similarity outlined above. Are we to presume that existential guilt also incorporates an allencompassing sense of having done wrong, or of being intrinsically flawed, and that both of these require the acknowledgment of the evaluative stance of others or of an internalized 'other'? This seems to be the case, at least partially, considering that in existential guilt "experience as a whole takes the form 'I am not what I should be"” (Ratcliffe 2015: 144).

If existential guilt consists in an all-encompassing sense of not being what one should be, or of being irredeemably flawed, we may rightfully question whether this sense is possible without any kind of evaluative judgment. It is arguable that such a sense presupposes at least a rudimentary grasp of concepts pertaining to moral agency, e.g. right and wrong, reproachability, blameworthiness, normative ideals, and so on. Without the application of evaluative concepts, the nature of existential guilt as guilt is ambiguous. Simply put, if the conceptually dependent senses of being reproachable, blameworthy, and so on are not considered necessary features of guilt, what does feeling guilty essentially consist in? It does not seem plausible that existential guilt could be a 'pure' bodily feeling, akin to feeling alive, fresh, or tired. However, if conceptual content is categorically ruled out, the theory needs to provide a more cogent explanation of the ways in which a set of diffuse bodily feelings or senses could constitute such a complex and developed sense of one's standing in the world. Crucially, the case of guilt indicates that some existential feelings might require certain

\footnotetext{
${ }^{4}$ Ratcliffe makes it clear that he is not interested in providing exact criteria for distinguishing between guilt and e.g. shame, remorse, and regret (2015: 134). Likewise, the single, unitary existential feeling that he designates as 'guilt' can also be expressed by "themes such as guilt, worthlessness, shame, and self-hate" (Ratcliffe 2015: 136). Be that is it may, my main concern here is not with labels, but rather with the phenomenology of the designated, unitary existential feeling. What kind of self-world relation does 'existential guilt' disclose, and is this possible without evaluative content?
} 
conceptual/evaluative schemes as conditions for their own intelligibility. All of this suggests that the non-conceptual nature of existential feelings merits reconsideration. ${ }^{5}$

\section{Conclusion}

Ratcliffe's theory of existential feelings has become prominent in illuminating an area of affectivity that many consider fundamental, yet at the same time, difficult to articulate cogently. When the world feels unreal, distant, or close, or when we feel at one with things, disconnected, or profoundly hopeless, traditional affective terms such as emotions and moods do no quite suffice in capturing what is at stake. In particular, the theory has proved valuable in dissecting the structure of psychopathological experiences. That said, Ratcliffe's characterization of existential feelings has also given rise to issues that merit further consideration.

In this article, I have identified and discussed three such issues. First, owing to Ratcliffe's basic dependency claim, the status of existential feelings as feelings is unclear in two respects, namely a) the sense in which they are felt as background bodily feelings, and b) the sense in which they are felt as possibility spaces. Second, the nature of the suggested bidirectional relationship between existential feelings and intentional experience remains uncertain, due to ambivalence over a) the extent to which intentional states are presumed to depend on existential feelings, and b) the identity of existential feelings as diffuse background senses, consciously salient episodes, or both. Finally, given the description of existential guilt, the non-conceptuality of existential feelings may not be as categorical as presumed.

I have not assessed the relative import of these concerns, i.e. whether one might pose more serious problems to Ratcliffe's theory than the other. In general, my overarching worry is that the theory places too much explanatory weight on bodily feeling. Simply put, the key claim that a specific type of bodily feeling tacitly determines the overall possibility and intelligibility of emoting and cognizing seems to extend the purview of feeling problematically far. In any case, it is beyond the scope of this article to develop in-depth responses to the raised concerns or to present an alternative view of what existential feelings might be.

\footnotetext{
${ }^{5}$ Jan Slaby and Achim Stephan (2008: 513) have suggested that existential feelings can have "very complicated, high-level contents - contents that only beings with sophisticated conceptual capacities are capable of instantiating". Accordingly, they have distinguished four different levels of existential feeling based on their "conceptual impregnation" and "situational specificity" (2008: 510-511). This taxonomy has not been put forward as a criticism of Ratcliffe's theory, so it seems, but as an assumedly unproblematic extension to it. Ratcliffe, however, has responded by stating he does "not subscribe to the view that there are 'levels' of existential feeling" in the suggested sense (2012: 44, see also 2015: 63fn). In his view, such categorizations reflect "different descriptions of existential feelings rather than different feelings" (2015: 63fn). The conclusion to be drawn is that, despite alternative proposals, Ratcliffe holds on to the categorically non-conceptual nature of existential feelings, leaving the presently explicated concern unresolved and open to discussion.
} 
On a final note, it would be unreasonable to suggest that we could assess Ratcliffe's theory vis-à-vis some settled overall account of experience, and then simply insist for the theory to be revised accordingly. Indeed, the issues I have examined in the specific framework of his theory are inseparably tied to broader ongoing philosophical debates about the nature of (affective) experience, its (pre-)intentional and bodily dimensions, and the role concepts play in its structuration. Viewed in this light, Ratcliffe's work on existential feeling has not only drawn much-needed attention to a fundamental dimension of affectivity, but also highlighted relevant questions about the overall structure of experience. As such, it is a valuable contribution to wider philosophical and phenomenological investigation. In recognition of this, my aims have been somewhat more limited and preliminary: to identify specific areas in Ratcliffe's account of existential feelings that would benefit from further critical discussion, and hence to open up new avenues for research on the topic.

\section{Acknowledgments}

I would like to thank Giovanna Colombetti, Matthew Ratcliffe, Jaakko Vuori, Nina Reiman, two anonymous reviewers, and academic audiences in Jyväskylä, Exeter, and Osaka for their extremely helpful comments on prior versions of this paper. I would also like to thank the Finnish Cultural Foundation for supporting my research financially. 


\section{Literature}

Andrejč, G. (2012). Bridging the gap between social and existential-mystical interpretations of Schleiermacher's 'feeling'. Religious Studies, 48 (3), 377-401.

Benson, O., Gibson, S., \& Brand, S. L. (2013). The Experience of agency in the feeling of being suicidal. Journal of Consciousness Studies, 20 (7-8), 56-79.

Bortolan, A. (2016). Affectivity and moral experience: an extended phenomenological account. Phenomenology and the Cognitive Sciences. Online first: DOI 10.1007/s11097-0169468-9.

Colombetti, G. \& Ratcliffe, M. (2012). Bodily feeling in depersonalization: A phenomenological account. Emotion Review, 4 (2), 145-150.

Fernandez, A. V. (2014). Depression as existential feeling or de-situatedness? Distinguishing structure from mode in psychopathology. Phenomenology and the Cognitive Sciences, 13 (4), $595-612$.

Gerrans, P. \& Scherer, K. (2013). Wired for despair: The Neurochemistry of emotion and the phenomenology of depression. Journal of Consciousness Studies, 20 (7-8), 254-268.

Guignon, C. (2009). The Body, bodily feelings, and existential feelings: A Heideggerian perspective. Philosophy, Psychiatry \& Psychology, 16 (2), 195-199.

Heidegger, M. (1927/1996). Being and Time (Sein und Zeit), trans. J. Stambaugh. New York: SUNY.

Manzotti, R. (2012). An externalist approach to existential feelings: Different feelings or different objects? In J. Fingerhut \& S. Marienberg (eds.), Feelings of being alive, 79-99. Berlin: De Gruyter. 
McLaughlin, B. P. (2010). Monothematic delusions and existential feelings. In T. Bayne and J. Fernández (eds.), Delusion and self-deception: Motivational and affective influences on belief-formation, 139-164. New York: Psychology Press.

Ratcliffe, M. (2005). The Feeling of being. Journal of Consciousness Studies, 12 (8-10), 4360 .

Ratcliffe, M. (2008). Feelings of being. Phenomenology, psychiatry and the sense of reality. Oxford: OUP.

Ratcliffe, M. (2010a). Depression, guilt and emotional depth. Inquiry, 53 (6), 602-626.

Ratcliffe, M. (2010b). The Phenomenology of mood and the meaning of life. In Goldie, P. (ed.), The Oxford handbook of philosophy of emotion, 349-371. Oxford: OUP.

Ratcliffe, M. (2012). The phenomenology of existential feeling. In Marienberg, S. \& Fingerhut, J. (eds.), Feelings of being alive, 23-54. Berlin: de Gruyter.

Ratcliffe, M. (2013a). What is it to lose hope? Phenomenology and the Cognitive Sciences, $12,597-614$.

Ratcliffe, M. (2013b). Why mood matters. In M. A. Wrathall (ed.), The Cambridge Companion to Heidegger's Being and Time, 157-176. NY: Cambridge University Press.

Ratcliffe, M. (2015). Experiences of depression: A study in phenomenology. Oxford: OUP.

Saarinen, J. A. (2014). The oceanic feeling: A case study in existential feeling. Journal of Consciousness Studies, 21 (5-6), 196-217.

Slaby, J. \& Stephan, A. (2008). Affective intentionality and self-consciousness. Consciousness and Cognition, 17, 506-513. 
Stephan, A. (2012). Emotions, existential feelings, and their regulation. Emotion Review, 4, $157-162$.

Stolorow, R. D. (2016). Matthew Ratcliffe: Experiences of depression: A study in phenomenology. Human Studies, 39 (2), 307-311.

Svenaeus, F. (2013) Depression and the self: Bodily resonance and attuned being-in-theworld. Journal of Consciousness Studies, 20 (7-8), 15-32.

Varga, S. \& Krueger, J. (2013). Background emotions, proximity and distributed emotion regulation. Review of Philosophy and Psychology, 4, 271-292.

Warsop, A. (2009). Existential feeling, touch, and 'belonging'. Philosophy, Psychiatry \& Psychology, 16 (2), 201-204.

Wynn, M. (2012). Renewing the senses: conversion experience and the phenomenology of spiritual life. International Journal for Philosophy of Religion, 72, 211-226. 